\title{
KETERSERDIAAN SARANA DAN PRASARANA PENUNJANG PEMBELAJARAN PJOK TINGKAT SMP SE-KECAMATAN PUPUAN
}

\author{
Luh Kd Giri Alvia Dewi Lestari ${ }^{1}$, I Gusti Lanang Agung Parwata², Ni Putu Dwi Sucita \\ Dartini $^{3}$
}

Prodi Pendidikan Jasmani Olahraga Kesehatan dan Rekreasi Jurusan Pendidikan Olahraga

Fakultas Olahraga dan Kesehatan

Universitas Pendidikan Ganesha

Kampus Jineng Dalem Undiksha Singaraja, Bali

Email : girialvia@gmail.com¹, lanang8@gmail.com², $\underline{\text { dwisucita@gmail.com³ }}$

\begin{abstract}
ABSTRAK
Penelitian ini bertujuan untuk mengetahui ketersediaan sarana dan prasarana olahraga di SMP Negeri se-Kecamatan Pupuan. Penelitian ini berjenis penelitian deskriptif kuantitatif melalui metode survei. Sampel studi ini sebanyak 6 SMP di Kecamatan Pupuan, Kabupaten Tabanan. Teknik mengumpulkan data ini melalui cara survei ke tiap sekolah kemudian mencatat data ketersediaan sarana prasarana PJOK dengan lembar observasi. Data dianalisis dengan analisis deskriptif yang kemudian mengklarifikasikan perolehan tipe data pada lembar observasi. Hasil penelitian menunjukkan sekolah dengan jumlah sarana dan prasarana PJOK dalam kategori baik sebanyak 3 sekolah $(50 \%)$, kategori cukup sebanyak 1 sekolah (16,67\%), dan kategori kurang sebanyak 2 sekolah (33,33\%). Kesimpulan dari penelitian ini adalah sarana dan prasarana di SMP se-kecamatan Pupuan masih banyak sarana dan prasarana yang kurang memadai, baik dari segi bentuk, kondisi, dan status kepemilikannya. Saran dari penelitian ini yaitu bagi sekolah agar mengetahui sarana dan prasarana sehingga tidak ada lagi masalah yang terjadi di sekolah, dan untuk guru yaitu sebagai acuan dalam persiapan perencanaan pembelajaran yang lebih inovatif dengan memodifikasi sarana dan prasarana sehingga tujuan pembelajaran itu tercapai.
\end{abstract}

Kata Kunci: ketersediaan sarana dan prasarana SMP se-kecamatan Pupuan

\begin{abstract}
The study aims to determine the availability of sports facilities and infrastructure in State Junior High Schools in Pupuan District. The study was a descriptive quantitative research through survey method. The sample of the study was 6 junior high schools in Pupuan District, Tabanan Regency. The technique of collecting data was used a survey to each school and records the data related to the availability of PJOK infrastructure with observation sheets. The data were analyzed using descriptive analysis which then clarified the acquisition of data types on the observation sheet. The results showed that three schools with the number of PJOK facilities and infrastructure in good categories $(50 \%)$, one school with sufficient categories $(16.67 \%)$, and 2 schools with inadequate categories $(33.33 \%)$. The conclusion of this research is that there are still many facilities and infrastructure in junior high schools in the Pupuan sub-district that are inadequate, both in terms of form, condition, and ownership status. The suggestions are the schools need to know the facilities and infrastructure so that there are no more problems that occur in schools, and for teachers, it can be a reference in preparing more innovative learning planning by modifying facilities and infrastructure so that the learning objectives are achieved.
\end{abstract}

Key words: the availability of facilities and infrastructure for junior high schools in Pupuan sub-district 


\section{PENDAHULUAN}

Proses pembelajaran adalah inti dari segala kegiatan pendidikan jasmani yang dilaksanakan di sekolah. Pembelajaran merupakan sebuah proses yang dilaksanakan guru untuk membelajarkan siswa dalam memperoleh serta memproses pengetahuan, sikap dan keterampilan (Dimyanti \& Mudjiyono, 2009).

Pembelajaran Pendidikan Jasmani. Olahraga dan Kesehatan (PJOK) merupakan pendidikan yang sangat penting. Menurut (Yulianda \& Fahrizi, 2018), pendidikan jasmani merupakan pembelajaran inti yang digunakan sebagai media dalam membentuk perkembangan motorik, keterampilan gerak dasar, serta menunjang siswa dalam penguasaan gerak secara efektif sehingga hal ini dapat meningkatkan kualitas hidup dan kebiasaan pola dalam kebugaran tubuh.

Dalam pembelajaran PJOK tentunya segala kegiatan inti dalam pembelajaran telah diprogramkan dengan baik dan terarah demi mencapai tujuan pembelajaran yang telah ditetapkan. Seluruh komponen pembelajaran telah dirancang dan dipersiapkan termasuk sarana dan prasarana yang digunakan. Komponen inti dalam proses belajar adalah sarana dan prasarana olahraga yang memadai, guru dan anak didik yang melakukan tugas dan tanggung jawab untuk bersama-sama mencapai tujuan pembelajaran. Menurut Undang-undang Nomor 20 tahun 2003 tentang sitem pendidikan nasional pada pasal 45 disebutkan bahwa "setiap satuan pendidikan formal dan non formal harus menyediakan sarana dan prasarana yang memenuhi.

Sarana atau alat adalah sesuatu yang diperlukan dalam pembelajaran, namun mundah dipindahkan, sedangkan prasarana adalah segala sesuatu yang diperlukan dalam pembelajaran PJOK yang bersifat permanen atau tidak dapat dipindahkan (Artanayasa, 2009). Selain itu (Pratama \& Wisnu, 2019) menyebutkan sarana dan prasarana merupakan salah satu alat bantu kegiatan pembelajaran agar tercapainya, karena sarana dan prasarana dianggap penting untuk kegiatan belajar mengajar dengan itu diharapkan bisa untuk mencapai tingkat kepuasan aktivitas gerak peserta didik.

Sarana dan prasarana yaitu faktor penting dalam menunjang keberhasilan pembelajaran PJOK. Namun faktanya, ketersediaan sarana dan prasarana yang memadai kerap kali menjadi permasalahan yang terjadi di sekolah termasuk sekolah menengah pertama negeri yang ada di Bali khususnya Tabanan. Permasalahan sarana dan prasarana PJOK di sekolah-sekolah disebabkan oleh sejumlah faktor (Nugraha \& Nurharsono, 2020). Faktor-faktor tersebut diantaranya kurangnya dana dana, atau area yang sempit, sehingga tidak memungkinkan untuk membuat lapangan diarea sekolah dan mereka menggunakan lapangan umum yang tersedia secara bersama-sama karena terbatasnya lapangan disekolah.

Beberapa penelitian tentang sarana dan prasarana pendidikan jasmani, olahraga dan kesehatan telah dilakukan. (Pratama, 2019) meneliti tentang ketersediaan sarana dan prasarana pendidikan jasmani, olahraga dan kesehatan di SD negeri segugus kecamatan Wonoayu, Sidoarjo. Hasil menunjukkan bahwa ketersediaan sarana dan prasarana di sekolah berkategori cukup karena tidak semua sekolah di gugus tersebut mempunyai sarana dan prasarana yang memadai. Sementara itu, (Saputra, 2018) meneliti Sarana dan Prasarana Pembelajaran Pendidikan Jasmani, Olahraga dan Kesehatan di Sekolah SMP se-Kecaatan Kebomas Kab. Gersik. Jenis penelitian yang digunakan merupakan survei. Dari hasil penelitian, dapat disimpulkan bahwa gambaran ketersediaan sarana dan prasarana olahraga yang ada di Sekolah SMP se-Kecamatan Kab Gersik dalam Kategori "B". Hal itu karena prasarana yang lebih banyak dan luas tanah menentukan hasil skor yang tinggi. Untuk hasil ketersedian tenaga pendidik yang ada di SMP se-Kecamatan Kebomas Kab. Gresik mendapatkan kategori "A" Hasil ini dibuktikan dengan status guru di SMP se-Kecamatan Kebomas Kab. Gresik sudah berstatus PNS dan mempunyai latar belakang lulusan S1 PJKR.

(Setiyoko \& Wisnu, 2019) meneliti tentang survei sarana dan prasarana pendidikan 
jasmani, olahraga dan kesehatan. Sampel yang digunakan yaitu 12 sekolah di kabupaten Pacitan yang dipilih melalui teknik random sampling. Metode yang digunakan adalah statistik kuantitatif dengan bantuan instrumen berupa angket PDPJOI. Hasil data menunjukkan bahwa sarana dan prasarana pendidikan jasmani di SMP Kabupaten Pacitan mendapatkan nilai rerata 155 dengan kategori $\mathrm{B}$ pada persentase $62 \%$. (Herman dan Riady, 2018) melakukan penelitian untuk mengetahui status kepemilikan sarana dan prasarana pendidikan jasmani di MTs Kabupaten Pangkep, mengetahui kelengkapan sarana dan prasarana yang ada serta untuk mengetahui kelayakan sarana prasarana yang ada di sekolah tersebut. Populasi studi ini merupakan seluruh MTs swasta di kabupaten Pangkep tahun 2017 dimana sampel yang dipilih yaitu sebanyak 15 sekolah. Dari hasil studi dinyatakan bahwa terdapat 3 MTs termasuk dalam kategori kurang dengan persentase $20 \%$, 9 sekolah berkategori cukup dengan persentase $60 \%$ dan 3 MTs termasuk kategori baik dan persentase sebanyak $20 \%$. Maka dapat disimpulkan bahwa sarana dan prasarana yang ada berada pada kategiru cukup sebesar $60 \%$.

Penelitian oleh (Saleh \& Ramdhani, 2020) melakukan studi terkait sarana dan prasarana pendidikan jasmani siswa kelas VIII SMP PGRI Barembeng di Kabupaten Gowa. Jenis penelitian ini merupakan penelitian deskriptif dengan metode survei. Data dikumpulkan dengan melakukan observasi dan tes dan dianalisa secara statistic melalui bantuan program SPSS. Dari hasil analisis didapatkan hasil sebagai berikut: 1) kondisi sarana dan prasarana di SMP PGRI Barembeng termasuk dalam kategori ideal; 2) tingkat kesegaran jasmani kelas VIII masuk dalam kategori sedang, dan 3) terdapat pengaruh antara sarana dan prasarana terhadap tingkat kesegaran jasmani siswa kelas VIII SMP PGRI Barembeng di Kabupaten Gowa.

(Sudibyo \& Nugroho, 2020) telah meneliti tentang sarana dan prasarana pendidikan jasmani untuk mengetahui keadaan sarana dan prasarana pembelajaran pendidikan jasmani di SMP Kabupaten Pringsewu tahun 2019. Penelitian ini menggunakan metode kualitatif dengan rancangan survei. Instrumenyang dugunakan berupa angket ketersediaan sarana dan prasarana olahraga. Hasil analisis data membuktikan bahwa keadaan sarana dan prasarana olahraga di 3 SMP kabupaten Pringsewu dalam kategori cukup ideal untuk mendukung pembelajaran. $\mathrm{Hal}$ ini disebabkan karena sejumlah guru telah membu berinovasi dan memanfaatkan bahan sederhana menjadi suatu inovasi alat pembelajaran pendidikan jasmani.

Dari beberapa hasil penelitian sebelumnya dapat dikatakan survei terkait ketersediaan sarana dan prasarana PJOK di sekolah sangat penting dilakukan. Hal ini berguna untuk mengetahui ketersediaan fasilitas yang memadai sehingga dapat digunakan masukan dan bahan pertimbamgan dinas terkait kebijakan program pengadaan sarana dan prasarana PJOK. Maka, peneliti tertarik untuk meneliti tentang ketersediaan sarana dan prasarana di SMP Negeri se Kecamatan Pupuan, Kabupaten Tabanan. Peneliti membatasi subjek penelitian ini hanya Sekolah Menengah Pertama (SMP) karena di Kecamatan Pupuan populasinya paling banyak ialah jenjang SMP. Penelitian ini bertujuan untuk mengetahui adanya ketersediaan sarana dan prasarama Pendidikan Jasmani Olahraga dan Kesehatan (PJOK) tingkat SMP di Kecamatan Pupuan.

\section{METODE PENELITIAN}

Metode penelitian adalah cara atau jalan yang ditempuh sehubungan dengan penelitian yang dilakukan, yang memiliki langkah-langkah yang sistematis. Menurut (Sugiyono, 2018) bahwa Metode Penelitian dapat diartikan sebagai cara ilmiah untuk mendapatkan data yang valid dengan tujuan dapat ditemukan, dikembangkan, dan dibuktikan, suatu pengetahuan tertentu sehingga dapat digunakan untuk memahami, memecahkan, dan menginspirasi masalah.

Jenis penelitian ini adalah penelitian deskriptif kuantitatif, dengan menggunakan metode survey. Menurut (Kanca, 2010) penelitian deskriptif adalah penelitian yang bertujuan untuk mendeskripsikan secara 
sistematis, daktual dan akurat terhadap suatu populasi, atau daerah tertentu, mengenai sifat-sifat dan fakta-fakta tertentu. Selain itu, instrumen penelitian ini menggunakan lembar observasi.

Populasi penelitian ini merupakan 6 SMP Negeri se kecamatan Pupuan, Kabupaten Tabanan. Seluruh populasi tersebut diantaranya SMP Negeri 1 Pupuan, SMP N 2 Pupuan, SMP N 3 Pupuan, SMP N 4 Pupuan, SMP N 5 Pupuan dan SMP N 6 Pupuan Satu Atap. Berdasarkan hal tersebut dapat dilihat bahwa jumlah populasinya terbilang sedikit yaitu 6 populasi, sehingga seluruh populasi menjadi sampel penelitian ini. Maka, dapat dikatakan sebagai penelitian Populasi atau population study/ cencus study dimana penelitian ini mengambil sampel dari keseluruhan jumlah populasi yaitu seluruh SMP se-Kecamatan Pupuan. Data dikumpulkan dengan cara observasi ke lokasi dan tepatnya dengan melakukan pengamatan langsung dengan sumber objek/ data penelitian dan juga mencatat suatu data yang diperlukan dilembar observasi. Selain observasi juga dilakukan dengan mengambil dokumentasi. Analisis yang digunakan dalam penelitian ini adalah deskriptif kuantitatif dengan cara mengklasifiksikan jenis data yang diperoleh dari lembar observasi.

Dalam penghitungan persentase tentang sarana dan prasarana digunakan rumus sebagai berikut:

$$
\begin{aligned}
& \mathrm{P}=\ldots \frac{f}{n} \mathrm{x} 100 \%, \\
& \text { Keterangan: } \\
& \mathrm{P}=\text { Persentase } \\
& \mathrm{F}=\text { Frekuensi data } \\
& \mathrm{N}=\text { Jumlah data }
\end{aligned}
$$

Kemudian perolehan data tersebut diklasifikasikan sebagai berikut:

Tabel 1. Kriteria Analisis Data

\begin{tabular}{ll}
\hline Rentangan Norma & Kategori \\
\hline$X>M+1,5 S D$ & Sangat Baik \\
$M+0,5 S D<X \leq M+1,5 S D$ & Baik \\
$M-0,5 S D<X \leq M+0,5 S D$ & Sedang \\
$M-1,5 S D<X \leq M-0,5$ & Kurang \\
$X \leq M-1,5 S D$ & Kurang sekali \\
\hline
\end{tabular}

\section{HASIL DAN PEMBAHASAN}

Sekolah Menengah Pertama Negeri seKecamatan Pupuan terdiri dari 6 sekolah yang seluruhnya berada di wilayah Kabupaten Tabanan, Bali. Sebagian besar sekolah memiliki sarana dan prasarana pendidikan jasmani milik sendiri meskipun jumlahnya ada yang cukup banyak, ada pula yang sedikit. Selain itu fasilitas pendidikan jasmani seperti lapangan sebagian besar sekolah masih meminjam, baik meminjam milik desa.
Dari hasil analisis data berdasarkan survei yang sudah dilaksanakan dapat dijabarkan hasil sebagai berikut yaitu 1) jumlah sarana dan prasarana pendidikan jasmani; 2) Jenis status kepemilikan sarana dan prasarana pendidikan jasmani; 3) Jenis kondisi sarana dan prasarana pendidikan jasmani; dan 4) Hasil jenis sarana dan prasarana pendidikan jasmani SMP Negeri sekecamatan Pupuan.

Hasil jumlah sarana dan prasarana pendidikan jasmani dapat dilihat secara lengkap pada Tabel 2: 
Tabel 2.

Jumlah Sarana dan Prasarana Pendidikan Jasmani

\begin{tabular}{|c|c|c|c|}
\hline No & Nama Sekolah & Skor & Kategori \\
\hline 1 & SMPN 1 Pupuan & 36 & Baik \\
\hline 2 & SMPN 2 Pupuan & 16 & Kurang \\
\hline 3 & SMPN 3 Pupuan & 39 & Baik \\
\hline 4 & SMPN 4 Pupuan & 33 & Baik \\
\hline 5 & SMPN 5 Pupuan & 13 & Kurang \\
\hline & SMPN 6 Pupuan & 30 & Sedang \\
\hline \multicolumn{2}{|r|}{ Jumlah } & \multicolumn{2}{|r|}{167} \\
\hline \multicolumn{2}{|r|}{ Mean } & \multicolumn{2}{|r|}{28} \\
\hline \multicolumn{2}{|r|}{ Standar Deviasi } & \multicolumn{2}{|r|}{107.8} \\
\hline
\end{tabular}

Tabel 2 menunjukkan bahwa terdapat 3 sekolah dengan sarana dan prasarana yang berkategori baik, 2 sekolah dengan kategori kurang dan 1 sekolah dengan kategori sarana dan prasarana yang sedang.

Untuk lebih jelasnya, frekuensi jumlah sarana dan prasarana pendidikan jasmani dapat dilihat pada Tabel 3.

Tabel 3.

Frekuensi Jumlah Sarana dan Prasarana Pendidikan Jasmani

\begin{tabular}{ccccc}
\hline No & Rentang Norma & Frekuensi & Persentase & Kategori \\
\hline 1 & $\mathrm{X}>44,2$ & 0 & 0.00 & Sangat baik \\
\hline 2 & $33,23<\mathrm{X} \leq 44,2$ & 3 & 50.00 & Baik \\
\hline 3 & $22,43<\mathrm{X} \leq 33,23$ & 1 & 16.67 & Sedang \\
\hline 4 & $11,63<\mathrm{X} \leq 22,43$ & 2 & 33.33 & Kurang \\
\hline 5 & $\mathrm{X} \leq 11,63$ & 0 & 0.00 & Sangat kurang \\
\hline Total & & 6 & 100 & \\
\hline
\end{tabular}

Berdasarkan Tabel 3, dapat diketahui bahwa jumlah sarana dan prasarana pendidikan jasmani dalam kategori kurang terdapat pada 2 SMP dengan persentase sebanyak 33,33\%\%.
Kemudian dalam kategori cukup terdapat 1 SMP dengan persentase sebanyak $16,67 \%$. SMP dengan jumlah sarana dan prasarana pendidikan jasmani dengan kategori baik terdapat 3 dengan persentase sebanyak $50 \%$.

Sedangkan status kepemilikan sarana dan prasarana pendidikan jasmani di SMP se-kecamatan Pupuan dapat dijabarkan pada Tabel 4 dan Tabel 5: 
Tabel 4.

Jenis Status Kepemilikan Sarana dan Prasarana Pendidikan Jasmani

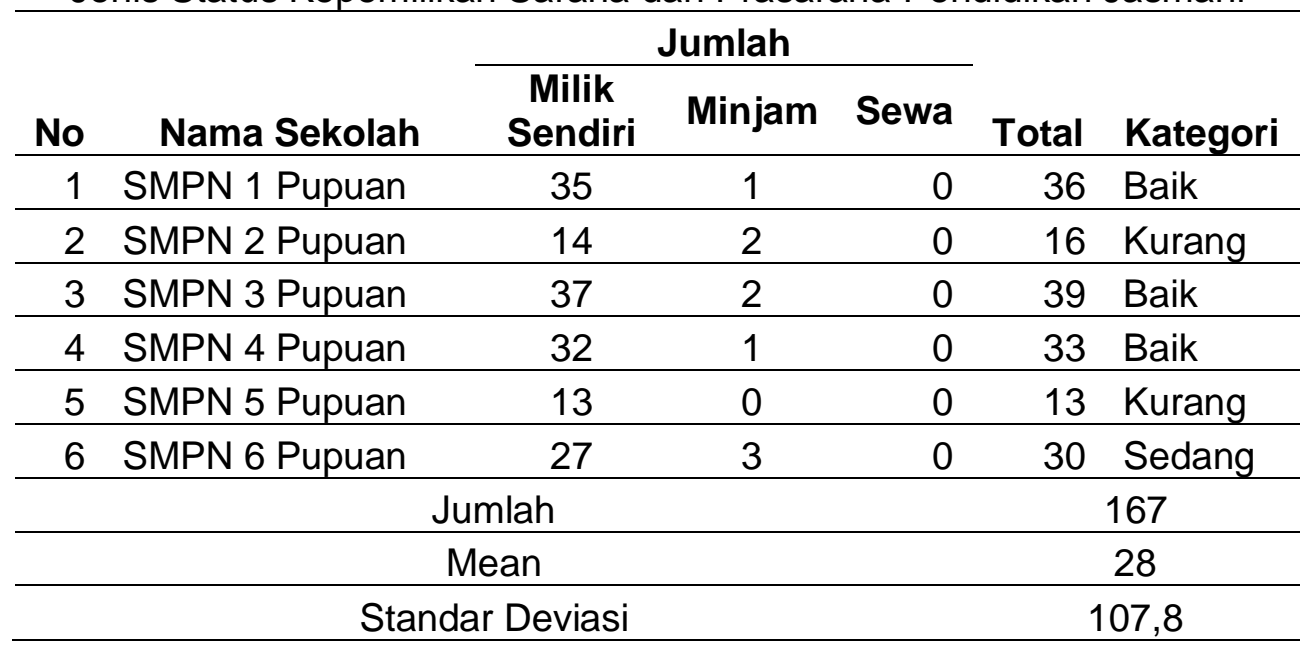

Tabel 5.

Rentang Norma, Frekuensi, Persentase dan Katagori Status Kepemilikan Sarana dan Prasarana Pendidikan Jasmani

\begin{tabular}{ccccc} 
No & Rentang Norma & Frekuensi & Percent & Katagori \\
\hline 1 & $\mathrm{X}>44,1$ & 0 & 0 & Sangat baik \\
\hline 2 & $33,23<\mathrm{X} \leq 44,1$ & 3 & 50 & baik \\
\hline 3 & $22,43<\mathrm{X} \leq 33.23$ & 1 & 16.67 & Sedang \\
\hline 4 & $11,63<\mathrm{X} \leq 22,43$ & 2 & 33.33 & kurang \\
\hline 5 & $\mathrm{X} \leq 11,63$ & 0 & 0 & $\begin{array}{c}\text { sangat } \\
\text { kurang }\end{array}$ \\
\hline Total & & 6 & 100 & \\
\hline
\end{tabular}

Berdasarkan Tabel 4, terdapat 5 sekolah dengan status kepemilikan sarana dan prasarana masih meminjam. Berdasarkan kategori nilai yang telah ditetapkan oleh peneliti dapat diketahui bahwa status kepemilikan sarana dan prasarana pendidikan jasmani dalam kategori kurang terdapat 2 SMP dengan persentase sebanyak 33,33\%. Kemudian dalam kategori cukup terdapat 1 SMP dengan persentase sebanyak $16,67 \%$. SMP dengan jumlah sarana dan prasrana pendidikan jasmani dengan kategori baik terdapat 3 dengan persentase sebanyak $50 \%$.
Maka, mengacu pada rentang norma pada Tabel 5, dapat dijelaskan bahwa status kepemilikan sarana dan prasarana pendidikan jasmani dalam kategori kurang terdapat 2 SMP dengan persentase sebanyak 33,33\%. Kemudian dalam kategori cukup terdapat 1 SMP dengan persentase sebanyak $16,67 \%$. SMP dengan jumlah sarana dan prasarana pendidikan dengan kategori baik terdapat 3 dengan persentase sebanyak $50 \%$.

Selain itu, kondisi sarana dan prasarana pendidikan jasmani dianalisa dengan dua kategori yaitu menggunakan skala perhitungan Baik (B) : Skor 2 dan Rusak (R) : Skor 1. Adapun hasilnya sebagai berikut: 
Tabel 6.

Penilaian dan Jenis Kondisi Sarana dan Prasarana Pendidikan Jasmani

\begin{tabular}{|c|c|c|c|c|c|c|}
\hline \multirow[b]{2}{*}{ No } & & \multirow[b]{2}{*}{ Nama Sekolah } & \multicolumn{2}{|c|}{ Jumlah } & \multirow[b]{2}{*}{ Total } & \multirow[b]{2}{*}{ Kategori } \\
\hline & & & Baik & Rusak & & \\
\hline & 1 & SMPN 1 Pupuan & 27 & 9 & 36 & Baik \\
\hline & 2 & SMPN 2 Pupuan & 15 & 1 & 16 & Kurang \\
\hline & 3 & SMPN 3 Pupuan & 39 & 0 & 39 & Baik \\
\hline & 4 & SMPN 4 Pupuan & 31 & 2 & 31 & Baik \\
\hline & 5 & SMPN 5 Pupuan & 12 & 1 & 13 & Kurang \\
\hline & 6 & SMPN 6 Pupuan & 25 & 5 & 30 & Sedang \\
\hline \multicolumn{5}{|c|}{ Jumlah } & \multicolumn{2}{|r|}{167} \\
\hline \multicolumn{5}{|c|}{ Mean } & \multicolumn{2}{|r|}{28} \\
\hline \multicolumn{5}{|c|}{ Standar Deviasi } & \multicolumn{2}{|c|}{107.8} \\
\hline
\end{tabular}

Tabel 6 menunjukkan kondisi sarana dan prasarana pendidikan jasmani di sekolah SMP se-kecamatan Pupuan. Dapat dilihat bahwa di SMP N 1 Pupuan 27 sarana dan prasarananya dalam kondisi kategori baik dan 9 buah dalam kondisi kategori rusak. Di SMP $\mathrm{N} 2$ Pupuan terdapat 15 buah berkategori baik dan 1 kondisi dalam kategori rusak. Di SMP N 3
Pupuan semua sarana dan prasaranya dalam kondisi baik. Namun di SMP $\mathrm{N} 4$ terdapat 31 buah berkategori baik dan 2 buah dengan kategori rusak. SMP N 5 Pupuan memiliki 12 sarana dan prasarana berkategori baik dan 1 dengan kategori rusak. Kemudian di SMP N 6 Pupuan memiliki 25 sarana dan prasarana yang baik dan 5 buah dengan kondisi rusak.

Tabel 7.

Rentang Norma, Frekuensi, Percent dan katagori

Kondisi Sarana dan Prasarana Pendidikan Jasmani

\begin{tabular}{ccccc}
\hline No & Rentang Norma & Frekuensi & Percent & Katagori \\
\hline 1 & $X>44,2$ & 0 & 0 & Sangat baik \\
\hline 2 & $33,23<X \leq 44,2$ & 3 & 50 & Baik \\
\hline 3 & $22,43<X \leq 33,23$ & 1 & 16.67 & Sedang \\
\hline 4 & $11,63<X \leq 22,43$ & 2 & 33.33 & Kurang \\
\hline 5 & $X \leq 11,63$ & 0 & 0 & Sangat kurang \\
\hline Total & & 6 & 100 & \\
\hline
\end{tabular}

Berdasarkan Tabel 7 yang menjelaskan mengenai kondisi sarana dan prasarana pendidikan jasmani yang telah dianalisis dan dilakukan olah data serta dikategorikan dalam tabel 4.6 oleh peneliti. Hasil yang didapat bahwa kondisi sarana dan prasarana pendidikan jasmani dalam

\section{PEMBAHASAN}

Berdasarkan hasil analisa dari survei terkait sarana dan prasarana pendidikan kategori kurang terdapat 2 SMP dengan persentase sebanyak 33,33\%\%. Kemudian dalam kategori cukup terdapat 1 SMP dengan persentase sebanyak $16,67 \%$. SMP dengan kondisi sarana dan prasrana pendidikan jasmani dengan kategori baik terdapat 3 dengan persentase sebanyak $50 \%$.

jasmani di SMP Negeri se-Kecamatan Pupuan Kabupaten Tabanan, dari 6 SMP 
Negeri se-Kecamatan Pupuan Kabupaten Tabanan untuk sarana/alat pendidikan jasmani tidak semuanya dimiliki, ada beberapa sarana/alat pendidikan jasmani sebagian kecil kondisinya yang rusak dan ada jenis sarana/alat pendididikan jasmani yang setatus kepemilikannya meminjam dan yang lainnya milik sendiri dan tidak ada yang menyewa. Ini dikarenakan sekolah lebih memprioritaskan sarana dan prasarana pendidikan jasmani yang lebih sering dipergunakan dan disukai oleh kebanyakan siswa pada umumnya, seperti bola sepak, bola voli, kelengkapan bulutangkis, kelengkapan atletik dan lainlain.

Hasil studi ini sesuai dengan hasil survei ketersediaan sarana dan prasarana pendidikan jasmani di MTs se-kecamatan Klojen kota Malang tahun 2017 (Khikmah \& Winarno, 2019). Data yang dianalisis secara deskriptif ini menunjukkan bahwa keseluruhan keadaan sarana dan pasarana di MTs se-Kecamatan Klojen Klojen Kota Malang adalah $38 \%$ memiliki sarana pembelajaran pendidikan jasmani dalam kriteria kurang baik. Hal ini dikarenakan sekolah lebih mengutamakan sarana dan prasarana pendidikan jasmani yang lebih sering dipergunakan dan disukai oleh kebanyakan siswa pada umumnya, seperti bola sepak, bola voli, kelengkapan bulutangkis, kelengkapan atletik dan lainlain.

Hasil penelitian ini sejalan dengan hasil dari penelitian survei yang dilakukan oleh (Setiyoko \& Wisnu) yang menyatakan bahwa sarana dan prasarana di SMP Negeri se-Kabupaten Pacitan mendapatkan nilai rata-rata 155 dengan kategori "B" pada persentase $62 \%$. Hal ini juga serupa dengan hasil penelitian (Sudibyo \& Nugroho, 2020) yang menunjukkan bahwa

\section{SIMPULAN}

Berdasarkan hasil analisa data dan pembahasan, dapat disimpulkan bahwa jumlah sarana dan prasarana pendidikan jasmani dalam kategori kurang terdapat 2 SMP dengan persentase sebanyak $33,33 \% \%$. Kemudian dalam kategori cukup terdapat 1 SMP dengan persentase sebanyak $16,67 \%$. SMP dengan jumlah kondisi sarana dan prasarana olahraga di ketiga SMP kabupaten Pring sewu cukup ideal untuk mendukung pembelajaran pendidikan jasmani, olahraga dan kesehatan. Hal ini dikarenakan guru olahraga terkait telah mampu berinovasi untuk membuat alat modifikasi olahraga yang memadai. Selain itu, hasil terkait survei sarana dan prasarana pendidikan jasmani juga ditemukan oleh (Herman \& Riady, 2018) bahwa terdapat 3 SMP/ MTs Swasta yang masuk dalam kategori kurang dengan perolehan persentase 20,0 \%. Terdapat 9 SMP/ MTs Swasta masuk dalam kategori cukup dengan persentase $60,0 \%$. Dalam kategori baik terdapat 3 SMP/ MTs Swasta dengan persentase sebanyak 20,0 \%. Maka dapat dikatakan sarana dan prasarana pendidikan jasmani berada pada kategori cukup sebesar $60,0 \%$.

Penelitian ini memberikan beberapa implikasi pada beberapa pihak diantaranya, sekolah terkait dan guru pendidikan jasmani. Hasil studi ini berimplikasi pada sekolah dimana sekolah lebih memperhatikan dan memperbaiki sarana dan prasarana pendidikan jasmani yang berada pada kondisi rusak sehingg mutu pendidikan jasmani dapat berlangsung dengan maksimal. Selain itu, membantu sekolah dalam mendata dan mengidentifikasi keberadaan kondisi dan status kepemilikan sarana dan prasarana pendidikan jasmani. Untuk guru pendidikan jasmani, hasil ini berimplikasi memberikan pengetahuan untuk mengetahui seberapa banyak dan seberapa besar dukungan sarana dan prasarana pendidikan jasmani di sekolah yang bersangkutan untuk menyusun kriteria ketuntasan minimal (KKM) mata pelajaran pendidikan jasmani.

sarana dan prasrana pendidikan jasmani dengan kategori baik terdapat 3 dengan persentase sebanyak $50 \%$. Terkait status kepemilikan sarana dan prasarana pendidikan jasmani dalam kategori kurang terdapat 2 SMP dengan persentase sebanyak 33,33\%. Kemudian dalam kategori cukup terdapat 1 SMP dengan 
persentase sebanyak $16,67 \%$. SMP dengan jumlah sarana dan prasrana pendidikan jasmani dengan kategori baik terdapat 3 dengan persentase sebanyak 50\%. Dan mengenai kondisi sarana dan prasarana pendidikan jasmani dalam kategori kurang terdapat 2 SMP dengan persentase sebanyak 33,33\%. Kemudian dalam kategori cukup terdapat 1 SMP dengan persentase sebanyak $16,67 \%$. SMP dengan kondisi sarana dan prasrana pendidikan jasmani dengan kategori baik terdapat 3 dengan persentase sebanyak $50 \%$.

Dari hasil penelitian ini beberapa saran dapat diajukan pada sekolah, guru pendidikan jasmani dan peneliti

\section{Daftar Pustaka}

Artanayasa. (2009). Buku Tp. Sarana dan Prasarana Olahraga. Singaraja: Universitas Pendidikan Ganesha.

Herman, H., \& Riady, A. (2018). Survey sarana dan prasarana pendidikan jasmani di smp/ mts swasta kabupaten pangkep. SPORTIVE: Journal of Physical Education, Sport and Recreation, 1(2), 27-35

Kanca, I. N. (2010). Metode Penelitian Pengajaran Pendidikan Jasmani dan Olahraga. Singaraja: Universitas Pendidikan Ganesha.

Khikmah, A., \& Winarno, M. E. (2019). Survei sarana dan prasarana pendidikan jasmani di madrasah tsanawiyah (mts) se-kecamatan klojen kota malang pada semester ganjil tahun 2017. Indonesia Journal of Sports and Physical Education, 1(1), 12-19.

Nugraha, K. A., \& Nurharsono, T., (2020). Survei sarana dan prasarana pendidikan jasmani di kecamatan kedu kabupaten temanggung. Indonesian Journal for Physical Education and Sport, 1(2), 382-388.

Pratama, H. W. (2019). Survei sarana prasarana pendidikan jasmani olahraga dan kesehatan sd negeri se-gugus 1 di kecamatan wonoayu kabupaten sidoarjo (ungraduated thesis). Universitas Negeri Surabaya, Surabaya. selanjutnya. Pihak sekolah disarankan untuk memperbaiki sarana dan prasarana yang kurang baik agar lebih optimal dalam fungsinya untuk menunjang pembelajaran pendidikan jasmani dan guru pendidikan jasmani diharapkan mampu memperluas pengetahuannya dalam memodifikasi dan berinovasi terkait sarana dan prasarana. Selain itu, peneliti selanjutnya disarankan untuk meneliti hal serupa dengan jumlah sampel yang lebih banyak, dengan tempat penelitian yang berbeda sehingga hasil yang didapat lebih dalam.

Saleh, M. S., \& Ramdhani, S. (2020). Survei sarana dan prasarana pendidikan jasmani dan tingkat kesegaran jasmani siswa kelas viii smp pgri barembeng kabupaten gowa. Journal Coaching Education Sports, 1(1), 51-64. doi:https://doi.org/10.31599/jces.v1i1.

Saputra, B. D. (2018). Survei ketersediaan sarana dan prasarana pembelajaran pendidikan jasmani, olahraga dan kesehatan di sekolah smp sekecamatan kebomas kab. Gresik (ungraduated thesis). Universitas Negeri Surabaya, Surabaya.

Setiyoko, H., \& Wisnu, H. (2019). Survei sarana dan prasarana pendidikan jasmani olahraga dan kesehatan di smp negeri se-kabupaten pacitan. Jurnal Pendidikan Olahraga dan Kesehatan, 7(2), 345-348.

Sudibyo, N. A., \& Nugroho, R. A. (2020). Survei sarana dan prasarana pembelajaran pendidikan jasmani olahraga dan kesehatan pada sekolah menengah pertama di kabupaten pringsewu tahun 2019. Journal of Physical Education (JouPE), 1(1), 18-24.

Sugiyono. (2018). Metode Penelitian Evaluasi. Yogyakarta: Alfabeta

Yuliandra \& Fahrizqi. (2018). Pengembangan model latihan jump shot bola basket. Journal of S.P.O.R.T, 2 (1), 36-72 